\title{
UM CONVITE À EXTENSÃO NAS ILHAS: ENTRE A REALIDADE E OS DESAFIOS DE UMA PROPOSTA DE PRÁTICA PEDAGÓGICA PARA LICENCIADOS DE CIÊNCIAS SOCIAIS
}

\section{AN INVITATION TO AN EXTENSION PROJECT ON THE ISLANDS: BETWEEN REALITY AND THE CHALLENGES OF A TEACHING PRACTICE PROPOSAL FOR SOCIAL SCIENCES GRADUATES}

Antonio Marcio Haliski*

Maria Lúcia Büer Machado*

Valéria Cristina Ferreira Haliski***

Patrícia Martins ${ }^{* * * *}$

\section{RESUMO}

Este artigo é um relato de experiência do trabalho desenvolvido em 2014 e tem como propósito atrair olhares de instituições/projetos para uma área, muitas vezes, invisibilizada por sua condição de ilha. A partir do desenvolvimento de um projeto de iniciação à docência para alunos do curso de Ciências Sociais, do Instituto Federal do Paraná, o artigo evidencia uma proposição cuja intenção é o desenvolvimento de práticas extensionistas nas ilhas do litoral do Paraná/Brasil, que envolvam a universidade-escolacomunidade, num processo de construção de conhecimentos e ações junto às escolas. Metodologicamente, a partir de uma análise qualitativa, mostraremos a realidade e os desafios no desenvolvimento de uma prática extensionista, tendo como referência o projeto que desenvolvemos (realidade objetiva) e os seus limites e possibilidades (pela nossa experiência), que aqui chamamos de desafios, no sentido da implantação de formas diferenciadas de educação, como é o caso da Educação do Campo, bem como a dificuldade em propagarmos uma educação pautada no buen vivir das comunidades (ACOSTA, 2012), e que, ao mesmo tempo, sirva para (re)significarmos a própria ciência a partir do que se entende por uma ciência pública (FLORIANI, 2015). Finalmente, como resultado da referida ação, esperamos contribuir para o debate em torno da importância de projetos educacionais voltados às realidades em que as escolas estão inseridas e, desta forma, instigarmos a proliferação de projetos de extensão, com este viés, no espaço analisado.

Palavras-chave: Projeto. Extensão. Ilhas. Escola

\footnotetext{
* Professor do Instituto Federal do Paraná (IFPR), PR - Brasil. Email: antonio.haliski@ifpr.edu.br

** Professora do Instituto Federal do Paraná (IFPR), PR - Brasil. Email: lucia.buher@ifpr.edu.br

*** Professora do Serviço Nacional de Aprendizagem Comercial (SENAC), PR - Brasil. E-mail: haliskival@yahoo.com.br

**** Professora do Instituto Federal do Paraná (IFPR), PR - Brasil. Aluna de Doutorado da Universidade Federal de Santa Catarina (UFSC), SC - Brasil. E-mail: patrícia.martins@ifpr.edu.br
} 


\section{ABSTRACT}

This paper reports on the work developed in 2014 and aims at drawing the attention of institutions/projects to an area which is many times neglected due to its insular location. The article highlights a proposition that has come about through the development of a project of introduction to teaching for Social Sciences students who study at the Federal Institute of Paraná. The purpose of this project is to develop extension practices on islands of the coast of Paraná/Brazil, which involve university-school-community in a process of knowledge construction and action within the schools. The methodology is based on qualitative analysis to study the reality and challenges to the development of an extension practice regarding the project developed (objective reality) and its limits and possibilities (in our experience). These challenges comprise the implementation of different forms of education, such as rural education and the difficulty of creating a model of education based on the peaceful coexistence of communities (Acosta, 2012), which at the same time can give a new meaning to science from what is meant by 'public science' (Floriani, 2015). Finally, as a result of our action, we hope to contribute to the debate on the importance of educational projects related to the realities that schools are inserted and thus encourage the proliferation of extension projects, with this view in the space analyzed.

Keywords: Project. Extension. Islands. School

\section{Introdução $^{1}$}

O trabalho visa trazer para o debate os desafios e as perspectivas do desenvolvimento do PIBID ${ }^{2}$, com viés extensionista, nas ilhas do litoral do Paraná, especificamente em uma escola na Ilha do Valadares, duas escolas na Ilha do Mel e uma na Ilha do Superaguí. Para tanto, partimos da descrição da proposta deste projeto, iniciado em março de 2014, passando pelas características gerais das escolas/comunidade, até chegarmos ao estágio atual em que nos encontramos. Neste artigo, realizamos uma análise do trabalho desenvolvido pelos coordenadores, supervisores e bolsistas do projeto.

$\mathrm{Na}$ perspectiva das ilhas, a ideia consistiu em trazer à tona questóes relativas à organizaçáo do trabalho e ao desenvolvimento do mesmo nas escolas. Para tanto, emergiram questóes centrais como a necessidade de um (re)planejamento constante de atividades/açóes, a construção de uma agenda de atividades/trabalhos que propiciassem o desenvolvimento do projeto PIBID e, ao mesmo tempo, o entendimento da dinâmica "natural" da escola em que o aluno bolsista atua, as transitoriedades dos bolsistas, bem como os seus afazeres no ensino superior e, como elemento-chave, o entendimento da realidade que a escola está inserida.

Este último quesito exige um grande esforço coletivo e tem como propósito mostrar que a escola pertence a uma realidade socioeconômica e ambiental que deve estar presente na sala de aula, via planos de ensino e Projeto Político Pedagógico (PPP). O desafio é o desenvolvimento de uma horizontalidade de saberes e práticas nas relaçôes universidade-escola-comunidade, pois a comunidade deverá participar ativamente na escola, ou seja, mostrar que a comunidade é a escola e não somente o lócus da escola.

Os saberes vernaculares ganham espaço/notoriedade. Por isso, danças, como o fandango caiçara, uso dos recursos naturais, práticas de pesca, construção de instrumentos como a rabeca (instrumento

1 Este texto, com algumas modificações, foi apresentado e debatido pelo primeiro autor, no IV Encontro Nacional sobre o ensino de Sociologia na Educação Básica, na UNISINOS, em São Leopoldo/RS.

2 O Programa Institucional de Bolsas de Iniciação à Docência (PIBID), a partir da CAPES, oferece bolsas de iniciação à docência aos alunos de cursos presenciais que se dediquem às atividades pedagógicas nas escolas públicas e que, quando graduados, se comprometam com o exercício do magistério na rede pública. O objetivo é antecipar o vínculo entre os futuros mestres e as salas de aula da rede pública. Com essa iniciativa, o PIBID faz uma articulação entre a educação superior (por meio das licenciaturas), a escola e os sistemas estaduais e municipais. (MEC, 2015). 
musical), embarcaçóes, comidas típicas, produção de alimentos, entre outros, são trazidos para a escola, ou melhor, servem para "inserirmos" a escola, de fato, na comunidade.

É uma proposta desafiadora, já iniciada por nós, e que encontra eco em várias partes da América Latina, visto que evidencia um movimento de (re)construçáo de currículos escolares/universitários que buscam dar um sentido à educação, qual seja, tratá-la enquanto bem comum a serviço de todos. Portanto, este texto caracteriza-se como um relato de experiência pautado em uma análise do desenvolvimento do projeto e não, necessariamente, um processo exaustivo de descrição da área ou das pessoas e/ou atividades onde foi desenvolvido. Nossa contribuição vem pelo tipo de abordagem que fizemos e nos seus limites e possibilidades.

\section{Sobre o projeto e as ilhas: da definiçáo das localidades, escolas e comunidades}

No período aqui apresentado, o subprojeto de Ciências Sociais/Habilitação em Sociologia, do Instituto Federal do Paraná - Campus Paranaguá, contou com três coordenadores (dois doutores em Sociologia/UFPR, uma doutoranda em Antropologia Social/UFSC) e 41 bolsistas (alunos dos três primeiros anos da graduação). Em razão das trajetórias distintas dos coordenadores, seja na pesquisa, extensão e, principalmente, no ensino, eles criaram uma agenda de reuniōes para a delimitação da área de atuação dos bolsistas, bem como a proposta e efetivação do PIBID nas escolas.

As primeiras discussóes giraram em torno da proposta do PIBID, visto que a formação do docente é a espinha dorsal. Daí duas açôes resultaram: a) entendimento de que os alunos iriam para as escolas e que estas estão inseridas em comunidades; e, b) formaçáo dos alunos, coordenadores e supervisoras ${ }^{3}$ para o desenvolvimento dos trabalhos. O elemento central é a comunidade e o esforço em darmos um sentido para a escola.

No primeiro caso, o entendimento dos coordenadores foi de que devíamos orientar nossas discussóes a partir das categorias território e conflitos. A razão para isso é que as escolas não podem ser dissociadas do entorno que estão inseridas. Nessa lógica, definimos como premissa o (re)conhecimento das realidades locais. Intencionamos levar os bolsistas a uma reflexão sobre a importância da valorização dos saberes locais, numa relação de horizontalidade com os saberes acadêmicos. Isto se deve ao fato de estarmos atuando em ilhas. A comunidade e os alunos assumem papel de destaque neste cenário.

Já no segundo caso, vem o entendimento de que os projetos pedagógicos das escolas deveriam ser debatidos à luz de suas influências teórico-metodológicas, ou seja, como foram construídas as diretrizes para o ensino nas escolas das ilhas. Para tanto, organizamos uma série de reunióes entre coordenadores, supervisores, bolsistas e pesquisadores das temáticas envolvidas, além de propiciarmos os primeiros contatos dos alunos com as escolas e com a comunidade do entorno.

No geral, pudemos definir este momento como de diagnóstico, em razão dos levantamentos bibliográficos, contato com as escolas, leitura de Projetos Pedagógicos,

3 As funções desempenhadas no PIBID estão organizadas da seguinte maneira: Coordenação de área, exercida pelo docente da Instituição de Ensino Superior; Supervisão, exercida por um docente da Educação Básica que atua na Escola onde o Programa é desenvolvido; e os acadêmicos, estudantes da Licenciatura, todos recebendo uma Bolsa fomentada pela CAPES. Vale ressaltar o papel Central que a CAPES atribui às ações da Supervisão, como elemento-chave para o sucesso do PIBID. 
contato com as comunidades, etc., e de formação, visto que estávamos nos preparando para a chegada nas escolas e, especificamente, em sala de aula.

O município de Paranaguá está localizado no litoral do Paraná e conta com aproximadamente 150 mil habitantes. Apresenta o maior potencial econômico dentre os sete que compóem o litoral paranaense (os outros são Antonina, Morretes, Guaraqueçaba, Pontal do Paraná, Matinhos e Guaratuba), com destaque para a atividade portuária. Neste enfoque, há a necessidade de se evidenciar a trama de relaçóes socioeconômicas e culturais que estão presentes no contexto. Falamos dos caiçaras, agricultores, familiares, farinheiras, pescadores artesanais, entre outros, ou seja, existe muito a se explorar além do segmento portuário.

São os filhos destes atores que estão nas escolas. Dito isso e considerando que o projeto PIBID não tem condiçóes de abarcar todas as escolas do município, optamos pela Ilha de Valadares ${ }^{4}$ e Ilha do $\mathrm{Mel}^{5}$. O outro município atendido, com uma escola na Ilha de Superagui ${ }^{6}$, foi o de Guaraqueçaba. A lógica permaneceu a mesma, ou seja, problematizar a partir das realidades onde as escolas se inserem. Neste último caso, temos um grande conflito entre a criação do Parque Nacional do Superagui (1989) e as comunidades de pescadores que se sentem prejudicados pelo mesmo.

A escola da Ilha dos Valadares apresenta uma orientação do seu plano Político Pedagógico voltada às Diretrizes Curriculares Estaduais (DCEs) no formato tradicional, ou seja, as disciplinas de História, Geografia, Sociologia, Física, etc. são ministradas por um professor de cada disciplina ${ }^{7}$. Cabe ao professor elaborar seu Plano de Trabalho Docente (PTD) de modo que atinja o proposto pelas DCEs.

Já nas ilhas do Mel e Superagui, o modelo adotado é o da Educação do Campo ${ }^{8}$. A lógica consiste na valorizaçáo dos saberes dos alunos, comunidade e professores, de modo que todos construam coletivamente, inclusive os planos de Trabalho Docente (PTDs). Grosso modo, o que baliza esta DCE é a organização em torno de eixos temáticos: a) trabalho - divisáo social e territorial; b) cultura e identidade; c) interdependência campo-cidade, questão agrária e desenvolvimento sustentável; d) organização política, movimentos sociais e cidadania?.

A crítica ao desenvolvimento deste modelo nas ilhas não vem pela Educação do Campo, mas pela organização curricular por áreas de conhecimento, visto que os professores apresentam muitas dificuldades em ministrar suas aulas (isso nos foi repassado pelos Supervisores, em reunióes do PIBID, e também pelos licenciandos). Na prática, um professor de História tem que "dar conta" dos conteúdos desta disciplina e de outras como a Geografia, pois "Os professores seráo contratados por área do conhecimento e ministrarão o conjunto das disciplinas que compóem a mesma” (PPP Ilhas, 2010, p.92).

Apesar da aparente ideia de interdisciplinaridade, esse encaminhamento pode funcionar muito mais como uma forma de racionalização de recursos por parte do Estado, considerando que um professor acaba desempenhando a função de vários. Exemplo, na

4 Colégio Estadual Cidália Ribeiro Gomes

5 Colégio Estadual Felipe Valentim e Colégio Estadual Lucy Requião

6 Colégio Estadual do Campo de Superagui

7 Disponível em: http://www.educadores.diaadia.pr.gov.br/modules/conteudo/conteudo.php?conteudo=1

8 Disponível em: http://www.educadores.diaadia.pr.gov.br/arquivos/File/diretrizes/diretriz_edcampo.pdf

$9 \mathrm{Na}$ Proposta pedagógica das escolas das ilhas do litoral paranaense, encontramos a divisão em eixos temáticos, da seguinte maneira: a) Modos de vida: trabalho, cultura(s) e identidade(s); b) territórios: natureza, poder e política; c) Saúde: hábitos e costumes. 
área de Ciências Humanas I, o professor pode ser formado em Sociologia, Filosofia, História, Geografia e ou Pedagogia. Embora se trate de outro documento, percebemse pistas desses mesmos encaminhamentos no texto proposto para a Base Nacional Comum Curricular, divulgada pelo MEC em 30 de julho de 2015. É lamentável, visto que a Educação do Campo traz uma proposta significativa de diálogo entre escola e comunidade. Por este motivo, cremos que ela deveria ser melhor trabalhada, a exemplo do que nos mostra Caldart (2012), ao afirmar a importância do protagonismo dos trabalhadores do campo na construção de políticas de educação, a partir de interesses sociais das comunidades.

Independentemente do formato das DCEs, a proposta do PIBID nas ilhas, na perspectiva da educaçáo do campo, consiste em possibilitar aos bolsistas a compreensáo de que a escola está inserida em uma realidade concreta e que a comunidade faz parte da escola, ou seja, ela deve ser atuante como, por exemplo, na participaçáo da construção dos PTDs. Noutras palavras, no plano da educação, as pessoas são encaradas como sujeitos de seu próprio destino ${ }^{10}$.

No plano da práxis pedagógica, a Educação do Campo projeta futuro quando recupera o vínculo essencial da formação humana e produção de existência, quando concebe a intencionalidade educativa na direção de novos padróes de relaçóes sociais, pelos vínculos com novas formas de produção, com o trabalho associado livre, com outros valores e compromissos políticos, com lutas sociais que enfrentam as condiçóes envolvidas nesses processos. (CALDARTI, 2012, p. 263). Foi esta perspectiva que orientou a construção do PPP das ilhas e também o desenvolvimento do PIBID. Isso é evidenciado pela afirmação da Supervisora do projeto em uma das escolas atendidas na Ilha do Mel.

Partindo da realidade do contexto escolar da educaçáo de campo na comunidade da Ilha do Mel, localizada no litoral paranaense, a 15 milhas do porto de Paranaguá, surgiu-se, entáo, o interesse e a preocupaçáo em entender e pesquisar as formas de conhecimento praticadas e desenvolvidas principalmente nesta comunidade ilhéu, que passa por vários problemas, tais como difícil acesso, falta de estrutura escolar, falta de capacitação dos profissionais, falta de material didático, falta de professores específicos para a área de conhecimento etc. O PIBID teve como principal objetivo, durante a realizaçấo do projeto, aproximar-se da realidade dos alunos, isto é, da comunidade escolar e conhecer suas identidades culturais, envolver-se diretamente com as problemáticas da escola, participar dos projetos políticos pedagógicos, e acima de tudo respeitar o local e toda a comunidade, para que desta forma o trabalho pudesse ser desenvolvido de forma satisfatória para todos envolvidos no projeto. Sendo assim, o PIBID realizou, através de atividades práticas e açóes participativas, vários encontros e dinâmicas que aproximaram os alunos ao projeto. (Supervisora na Ilha do Mel, 2014)

Discutir o formato do currículo é indispensável em uma proposta, levantada por nós, de inserção da comunidade, de fato, na construçáo e abordagens de conteúdos a serem ministrados em sala. Em hipótese alguma isso caracteriza uma maneira de deslegitimar o professor, isto sim, de criar espaço para que o professor se inteire das questóes comunitárias e possa abordá-las, com viés científico, em sala de aula. É a concepção de uma ciência pública. Isso também evidencia uma tendência nas academias, que é a valorização de

10 Não é o propósito deste texto, mas a Educação do Campo e sua organização curricular nas escolas das ilhas merece uma discussão específica, a exemplo do que fez Rossi (2014), em seu livro Educação do campo: questões de luta e pesquisa. 
saberes vernaculares ou, noutras palavras, de povos originários e populaçóes tradicionais. Isso pode ser evidenciado em grupos como o Interconexóes ${ }^{11}$ (Universidade Estadual de Ponta Grossa - UEPG) ou mesmo a Rede Internacional Casla-Cepial ${ }^{12}$ (rede composta por dezenas de instituiçóes de ensinos, movimentos sociais, etc., da América Latina).

\section{Desafios atuais da proposta}

Assumir o projeto PIBID por si já é um desafio, pois a sua lógica de funcionamento pressupóe um grande avanço na formaçáo de docentes, haja vista que o aluno bolsista passará a viver uma realidade de escola antes do exercício de sua profissão como professor. Desafio maior ainda é a proposição de uma relação sólida, via extensão, entre escolacomunidade-universidade. Isso se dá muito em razão da nossa insistente tendência de reproduçáo de modelos eurocêntricos ou mesmo de um famigerado movimento de racionalização da sociedade ocidental. Isso se manifesta de distintas formas em nossa sociedade, ou seja, para a formação do futuro professor, especificamente no desenrolar do PIBID ilhas, nos deparamos com alguns grandes obstáculos que, obviamente, abrem novas perspectivas de trabalhos.

Nos referimos especificamente:

a) dificuldade encontrada pelos Coordenadores, respeitadas suas trajetórias, na articulação de uma proposta de trabalho que se enquadre com suas perspectivas de trabalho;

b) seleçáo de supervisores nas escolas, que aceitem e queiram desenvolver o projeto PIBID, nesta proposta;

c) estabelecimento de uma agenda de discussóes que obedeça a carga horária mínima de trabalho dos bolsistas e que, ao mesmo tempo, lhes permita conciliar com seus trabalhos (muitos alunos dependem de liberaçóes de seus patrôes para desenvolverem as atividades) e mesmo as rotinas de sua graduação;

d) gerenciamento de tempo e o desenvolvimento dos trabalhos de forma "orquestrada" entre coordenadores, supervisores, bolsistas PIBID, alunos das escolas e com a comunidade;

e) desenvolvimento de um canal eficiente de comunicaçáo entre os participantes (atas, redes sociais, etc.);

f) construção de um projeto de educação pautado numa ciência pública - por isso entendemos uma ciência a serviço das comunidades.

Outra situação desafiadora que encontramos refere-se à proposta do PPP das ilhas, visto que sugere que o professor rompa com a disciplinaridade da sua matéria, ou seja, o professor clássico de Sociologia, Geografia, entre outros, passa a ministrar seu conteúdo dentro das humanidades. Isso significa que sua disciplina deverá possuir relaçáo direta com outras, como a História e a Geografia. Na prática, o professor deverá montar um plano de trabalho docente (PTD) que contemple as diretrizes de outras ciências, lembrando, ainda, que estes conteúdos dos PTDs deverão estar atrelados à realidade da comunidade em que a escola está inserida.

Notadamente, isto é muito interessante, mas o desafio está no fato de contribuir para que os bolsistas compreendam esta dinâmica. Enfim, o objetivo do PPP das ilhas

11 Disponível em: http://gpinterconexoes.blogspot.com.br/

12 Disponível em: http://redecaslacepial.blogspot.com.br/

UM CONVITE À EXTENSÃO NAS ILHAS: ENTRE A REALIDADE E OS DESAFIOS DE UMA PROPOSTA DE PRÁTICA PEDAGÓGICA PARA LICENCIADOS DE CIEENCIAS SOCIAIS 
pressupóe uma educação que visa à autonomia e cidadania plena, tendo como base o diálogo entre os conhecimentos dos moradores das ilhas, fundamentados em seus saberes e identidades.

Ao problematizar as questóes curriculares das Licenciaturas e as necessárias e urgentes transformaçóes que o tema exige, a pesquisadora Bernadete Gatti aponta para os desafios que estấo postos para uma real aproximação entre a Formação Inicial Docente e a atuação desses futuros profissionais na Educação Básica:

\begin{abstract}
Está colocada uma questão em busca de resposta: por que mudanças profundas não ocorrem nesses cursos uma vez que há muito, e por muitos estudos, temse falado em crise das licenciaturas pelas suas fragilidades formativas? [...] As políticas e as práticas relativas à formação inicial de docentes para a educação básica têm resistido há um século na conservação de uma estrutura curricular e institucional funcionando à margem dos movimentos socioculturais e históricos na atualidade, que evidenciam profundas mudanças na sociedade. A estrutura da educação básica mudou, os segmentos sociais que nela se inserem mudaram, a idade de inserção das crianças e adolescentes mudou. Essas mudanças exigem da formação de professores mudanças radicais. Mudanças que, de fato, permitam que os seus licenciandos se inteirem mais profundamente de questóes educacionais, dos aspectos de desenvolvimento cognitivo e social dos alunos que adentram à escola básica e suas motivaçóes, questóes relativas à escola e às redes de ensino, ao seu currículo, entre outros aspectos. (GATTI, 2013, p.64)
\end{abstract}

Assim, é fundamental uma agenda com açôes concretas, em que possamos superar os desafios existentes - a experiência do PIBID de Sociologia nas Ilhas do Litoral do Paraná, além de proporcionar o contato dos licenciandos com a especificidade regional dos desafios da Educação Básica nas Ilhas, evidenciou concomitantemente para uma necessária aproximação das temáticas abordadas na organização curricular do curso de Ciências Sociais, com os desafios inerentes a tal experiência pedagógica.

No plano prático, realizamos vivências nas comunidades através de festas, rituais, participaçôes em reunióes com as comunidades, etc., de modo que os bolsistas se integrem na dinâmica da escola dentro das comunidades que elas se encontram. Isso para que as demandas locais possam estar presentes nos planos de trabalhos docentes, tanto da escola da Ilha dos Valadares (que obedece ao formato clássico) quanto das escolas da Ilha do Mel e Superagui. Relatórios de vivências, gravaçóes de entrevistas, fotografias, vídeos, entre outros, são as ferramentas que auxiliam no processo.

O principal empecilho encontrado no desenvolvimento do PIBID ilhas é a distância das escolas em relação ao Instituto Federal. Assim, os alunos bolsistas do Superagui tinham que sair quinta-feira e retornar ao campus domingo. Esta forma de trabalho prejudicava a frequência nas aulas da licenciatura, para atuar no projeto. A ausência dos alunos bolsistas vez ou outra em sala de aula acabava por comprometer o seu rendimento nos componentes curriculares daquele dia, ou seja, de certo modo, o que estávamos fazendo prejudicava a formaçáo acadêmica dos envolvidos. Na prática isso é um contrassenso, visto que a proposta do projeto é fortalecer a formação inicial e não fragilizá-la.

No caso da Ilha do Mel, os alunos bolsistas tinham que sair muito cedo para pegar a embarcação até a ilha, lá desenvolviam suas atividades e retornavam a tarde e, ainda, tinham aulas à noite. Assim como no caso anterior, verificamos que esta prática prejudicava os alunos bolsistas, que se encontravam exauridos por esta jornada. Isso não 
ocorreu na Ilha dos Valadares, pelo fato de estar separada apenas por uma ponte da área central de Paranaguá.

Não há como descrever a riqueza dos aprendizados que os alunos obtiveram na Ilha do Mel e no Superagui. Desde as reunióes com a comunidade até a presença em sala de aula; contudo, a distância foi um fator fundamental para encerrarmos o projeto e para que escolhêssemos outras escolas mais próximas do campus (momento atual). Mantivemos apenas a escola da Ilha dos Valadares.

A nova etapa deverá ser analisada em outro momento, que não é o deste texto. Estamos reproduzindo a mesma perspectiva de se discutir a escola/universidade na e pela comunidade. Esta perspectiva está ancorada em autores como Floriani (2015), ao defender o que chama de uma ciência pública e pertinente, ou seja, que tenha como um dos propósitos o bem comum, ou como diria Acosta (2012), o buen vivir.

\section{Consideraçóes finais}

A riqueza do PIBID nas Ilhas está em sua dinâmica. A relação comunidade escola passa a ser ressignificada por todos os envolvidos e, ao mesmo tempo, permite-nos projetar açóes que se materializam no sentido da construção de uma escola de base comunitária.

Após a execução dos trabalhos desenvolvidos pelo PIBID, pode-se verificar uma grande dificuldade na questáo da participaçáo efetiva dos alunos. Desta forma, foi necessário promover discussões entre os docentes da escola, para discutir açôes práticas e intervençôes pedagógicas, como forma de amenizar os problemas disciplinares [...] apesar desta problemática, os alunos que realmente se mostraram interessados pelo projeto, ou seja, que se envolveram diretamente nas atividades e nas oficinas ofertadas, puderam interagir, entrar em contato direto com a comunidade em que está inserido, analisar sua realidade. Assim, eles conseguiram a participaçáo da comunidade local no projeto e a realização das açôes propostas pelo PIBID [...] com total apoio da comunidade. (Supervisora da Ilha do Mel, 2014) ${ }^{13}$

Temas como pesca artesanal, manifestaçōes religiosas e artísticas, movimentos sociais, instituiçôes, entre outros, passam a ser tratados também com o olhar dos alunos/ comunidade e não somente pelos professores, via autores contemporâneos e clássicos. Isso não significa o abandono da ciência, pelo contrário, trata-se do seu sentido prático, numa relação dialógica com os saberes tradicionais.

$\mathrm{Na}$ relaçáo universidade-comunidade-escola evidencia-se a necessidade do desenvolvimento de uma ciência que, de fato, seja pública e se manifeste na prática dos professores em seus espaços de trabalho. O PIBID propicia, nesse sentido, enxergarmos essas múltiplas vias que unem a população, os saberes tradicionais, saberes científicos, enfim, a escola (já entendida como parte da comunidade) e a universidade. Resta-nos trabalhar com tais informaçóes e propiciarmos as mudanças cabíveis.

De forma geral, podemos inferir que o projeto se resume à necessidade de reorganização pedagógica do calendário e do currículo da escola e da universidade. No caso das ilhas, isso ficou evidente em várias situaçôes, como por exemplo, durante a pesca da tainha, em que muitos alunos ajudam seus pais, ou seja, a escola náo pode 
desconsiderar os valores/práticas tradicionais neste processo ou, noutro caso, no mês de novembro temos a reprodução de butucas (moscas), que afetam diretamente na qualidade das aulas.

Outra situaçáo refere-se ao período de temporada, quando o movimento turístico aumenta nestes locais. Enfim, são situaçōes que extrapolam os encaminhamentos pedagógicos, mas que interferem de modo prático no cotidiano escolar, evidenciando a necessidade de um calendário diferenciado, caso contrário o risco da evasáo é eminente.

Com relação ao currículo das universidades e escolas, o que vemos é uma desconexão entre o que se aprende (universidade) e o que se ensina (escola). Logo, as teorias apreendidas não reproduzem um impacto significativo nas comunidades. A questão que estamos focando mostra a necessidade de darmos um sentido à escola/universidade. $\mathrm{O}$ que aprendemos e como ensinamos? Esta ciência das universidades serve a quem e para quê? Repetimos, não estamos negando a academia, mas tentando (re)orientá-la para a comunidade.

Um dos aspectos que devem ser evidenciados é a importância da imbricação das várias instâncias nesse processo - as políticas públicas educacionais promovidas pelo Estado Brasileiro, como o PIBID, a ação das Instituições Superiores de Formação Docente, e as Escolas da Educaçáo Básica - foi essa configuração que propiciou, a partir do investimento público, a valorização da Formação Docente inicial docente e uma real aproximação entre as Instituiçóes comprometidas com a Educação Pública.

Especificamente sobre o enfoque extensionista, enfatizamos que isso está ligado mais à trajetória dos coordenadores do projeto ora apresentado do que à proposta do PIBID, porém, entendemos que temos muito que aprender sobre extensão e seus impactos positivos nas escolas, comunidades e universidades. 


\section{Referências}

ACOSTA, A. Buen Vivir. SumakKawsay, Una oportunidad para imaginar otros mundos. Quito: Abya-Yala, 2012.

BRASIL. Ministério da Educação. PIBID. Disponível em: http://portal.mec.gov.br/index.php?option=com content\&view=article\&id=233:pibid-apresentacao\&catid=155:pibid\&ltemid=467. Acesso em: 18/06/2015.

CALDART, R. S. Educação do Campo. In: CALDART, R. S; PEREIRA, I.B.; ALENTEJANO, P.; FRIGOTTO, G. (Orgs.). Dicionário de educação do campo. Rio de Janeiro, São Paulo: Escola Politécnica de Saúde Joaquim Venâncio. Expressão Popular, 2012.

FLORIANI, D. Las ciencias sociales en América Latina: lo permanente y transitorio, preguntas y desafíos de ayer y hoy. Polis, Revista Latinoamericana. Disponível em: https://polis.revues.org/11149?lang=pt. Acesso em: 22/03/2015.

GATTI, B. Educação, escola e formação de professores: Políticas e Impasses. Educar em Revista, Curitiba, Brasil, n. 50, p. 51-67, out./dez. Editora UFPR, 2013.

PARANÁ. Diretrizes Curriculares da Educação do Campo. Curitiba: Secretaria de Estado da Educação SEED, 2006.

. Proposta Pedagógica das escolas das Ilhas do litoral Paranaense. Curitiba: Secretaria de Estado da Educação - SEED, 2009.

ROSSI, R. Educação do campo: questões de luta e pesquisa. Curitiba: CRV, 2014. 